\title{
Prevalence of Parasitic Infestation in Diabetic Patients in Tertiary Care Hospital
}

\author{
Dhruba Hari Chandi ${ }^{1}$, Dhruba Hari Chandi ${ }^{2^{*}}$ and Sucheta J. Lakhani ${ }^{1}$ \\ ${ }^{1}$ Department of Microbiology, SBKS Medical Institute and Research Centre, \\ Piparia, Gujarat, India \\ ${ }^{2}$ Department of Microbiology, Jawaharlal Nehru Medical College, Sawangi (M), Wardha, \\ Maharashtra, India \\ *Corresponding author
}

\section{Keywords}

Prevalence,

Diabetes mellitus,

Parasitic

Infestation,

Protozoa,

Helminthes

\section{Article Info}

Accepted:

08 January 2020

Available Online:

10 February 2020

\section{A B S T R A C T}

Especially in immunocompromised and immunosuppressive patient's infection of intestinal parasites are an important cause of morbidity and mortality worldwide. In developing countries this become as a major public health problem. Diabetes mellitus (DM) is a metabolic non-communicable disease characterized by hyperglycemia, caused by insufficient insulin secretion, action of impaired insulin or both. Many studies have been reported the problems of diabetics are increasing and have been reported to be immunocompromised. The main objective of this study is to determine the prevalence of parasites among DM patients. This is a cross-sectional study carried on diabetic patients who visit in the hospital. Total 110 DM patients were included in this study. Random patients were selected and fresh stool specimens were collected and processed in microbiology laboratory by Microscopy, Formalin-Ether Concentration and Modified Ziehl Neelsen staining techniques. Total 110 stool sample were collected. Among all 110 DM patients total 110 stool sample were process from which total $15(13.6 \%)$ sample were positive for parasite. Out of 110 patients $70(63.6 \%)$ were female and $40(36.4 \%)$ were male. In this study DM patients with the age range from 20 years to 70 years old were included with the mean age of $48.2 \pm 9$.1years old [Standard Deviation (SD) is 13.1]. Between the age group 50-60 years old was more in number. Out of 110 samples $15(13.6 \%)$ were diagnosed as parasitic infection with one having mixed infection. Different parasites were identified as Entamoeba histolytica, Giardia lamblia, Ascaris lumbricoides \& Cryptosporidium parvum with three protozoans and one helminthes. Most common parasite were Entamoeba histolytica 8(7.3\%) followed by Cryptosporidium parvum 5(4.5\%) Ascaris lumbricoides 2(1.8\%) and Giardia lamblia (0.9\%). In this study female $11(15.7 \%)$ showed higher prevalence than male 4(10\%). The age group $50-60$ years old showed the highest prevalence 5(14.3\%). In this study Single and Mixed Parasitic Infections was also found in Diabetic Patients. In the mixed infection Entamoeba histolytica + Cryptosporidium parvum was found only in 1 patient and other as single infection in 14 patients. Single infections 14(12.7\%) were more prevalent than mixed infections $1(0.9 \%)$. Entamoeba histolytica was found maximum as single infections. In this study the prevalence of parasitic infection among DM patients was $13.6 \%$. There is increased risk of parasitic infection in DM patients especially with Entamoeba histolytica an opportunistic infection. The diagnosis of Cryptosporidium parvum indicates a weakened immune system in diabetic's patients. Hence for parasitic infection in DM patients should be screened routinely as stool examination for the social welfare. 


\section{Introduction}

In developing countries intestinal parasitosis constitutes a major public health problem as it is major cause of morbidity and mortality, though there is increasing population of immunocompromised people. This is also considering as a major health problem worldwide $^{1}$. Especially in developing countries like India where there is lack of health education, poor sanitary conditions and lack of information about the contamination of food and water sources subsequent prolongation of parasite cycles ${ }^{2}$.

There are many researches which showed that immune suppression as primary immunodeficiency in human immunodeficiency virus (HIV) infection and use of immunosuppressive drugs such as posttransplantation increases the risk of infection, chronic carriage states. However patients with any weakness of immune system such as metabolic disorders and chronic internal diseases were considered as higher risks of infectious diseases ${ }^{3,4,5}$. Immunocompromised group also consist of the patients that suffering from chronic renal disease, which later causes irreversible and increasing loss of kidney function that lead to need for renal replacement therapy ${ }^{6,7}$.

Diabetes mellitus (DM) is define as a group of metabolic non-communicable diseases characterized by high blood glucose level (hyperglycemia) either because of insufficient insulin secretion or because cells do not respond to the insulin that is produced or impaired insulin action or both ${ }^{8}$. Diabetes mellitus is classified into two types as Type 1 Insulin-Dependent Diabetes mellitus (IDDM) and Type 2 Non-Insulin-Dependent Diabetes mellitus (NIDDM). This high blood sugar produces the classical symptoms of polyuria, polydipsia and polyphagia. Worldwide Diabetes become as one of the most frequent metabolic diseases which distributed in various populations and appears to be increasing its prevalence rapidly ${ }^{9}$.

According to Jean Claude Mbanya; President of the International Diabetes Federation (IDF) "In every country and in every community worldwide, we are losing the battle against this cruel and deadly disease". In 2013, studied showed that around 382 million people had diabetes and without essential prevention and management programs this number is expected to rise to 592 million by 2035. Around $80 \%$ of people with diabetes live in low and middle income countries ${ }^{10}$.

According to the study, India leads the world largest number of diabetic subjects earning the dubious distinction of being termed the "diabetes capital of the world. In 2006 "According to the Diabetes Atlas published by the International Diabetes Federation, in India currently about 40.9 million number of people with diabetes and is expected to rise to 69.9 million by 2025 unless urgent preventive steps are taken ${ }^{11}$. Diabetic patients have been reported to be immunocompromised ${ }^{2,12,13,14}$. Parasitic infection in immunosuppressed patients have been obtained as increasing attention as important opportunistic pathogens responsible for clinical infections ${ }^{15,16}$.

The purpose of this study is to evaluate the prevalence of intestinal parasitic infections among DM patients.

\section{Materials and Methods}

This study was conducted in department of microbiology at CCMMC, Bhilai; Durg district of Chhattisgarh state located in Central East India. This cross-sectional study was carried on diabetic patients who visit in hospitals from March 2019 to August 2019. From all the DM patients study were carried out to determine the prevalence of intestinal parasites. 
Randomly patients with DM were selected. Total 110 diabetic patients with either type I or II and on anti-diabetic treatment were included in this study. During the study period detail data of patients were obtained from the patients as well as from the medical record department (MRD). From the entire patients stool sample were collected in a clean, dry, leak proof, tight lid plastic container containing a small spoon labeled with name and identification number which was immediately brought to the microbiology laboratory at department of microbiology for processing. Stool sample were analyzed by following three heading: Macroscopic Examination, Microscopic Examination and Concentration technique as Formal ether concentration

\section{Macroscopic Examination}

Samples were analyzed by macroscopically for presence of blood, mucus, adult worms, segments of tapeworm and larvae. The consistency of stool as formed, loose or watery or soft with color and odor were recorded.

\section{Microscopic Examination}

All stool samples were examined by direct microscopic examination. Saline and Iodine wet mount were performed for the presence of parasitic cysts, trophozoites and ova and larva. Modified Ziehl-Neelsen (MZN) stain was also performed for detection and identification of intestinal coccidians Cryptosporidium parvum, Cyclospora and Isospora belli ${ }^{15}$. Concentration technique as Formal ether concentration method was also done and examined by microscopically for presence of parasites (wet mount and iodine preparation). Positive stool sample with presence of parasites were informed for treatment.

\section{Results and Discussion}

Total 110 stool sample were collected. Among all 110 DM patients total 110 stool sample were process from which total $15(13.6 \%)$ sample were positive for parasite. Out of 110 patients $70(63.6 \%)$ were female and $40(36.4 \%)$ were male as shown in table. In this study DM patients with the age range from 20 years to 70 years old were included with the mean age of $48.2 \pm 9.1$ years old [Standard Deviation (SD) 13.1]. Between the age group 50-60 years old was more in number as shown in the table below table no 2. Mean deviation of mean is 11.276. Out of 110 samples $15(13.6 \%)$ were diagnosed as parasitic infection with one having mixed infection. Different parasites were identified as Entamoeba histolytica, Giardia lamblia, Ascaris lumbricoides \& Cryptosporidium parvum with three protozoans and one helminthes.

Most common parasite were Entamoeba histolytica 8(7.3\%) followed by Cryptosporidium parvum 5(4.5\%) Ascaris lumbricoides 2(1.8\%) and Giardia lamblia 1 $(0.9 \%)$ as shown in table no: 3 . In this study female $11(15.7 \%)$ showed higher prevalence than male 4(10\%). The age group $50-60$ years old showed the highest prevalence $5(14.3 \%)$. In this study single and mixed parasitic infection was also found in Diabetic patients. In the mixed infection Entamoeba histolytica + Cryptosporidium parvum was found only in 1 patient and other as single infection in 14 patients as shown in tables no 4. Single infections $14(12.7 \%)$ were more prevalent than mixed infections $1(0.9 \%)$. Entamoeba histolytica was found maximum as single infections. 
Table.1 Distributions of total no of Diabetic patients according to gender

\begin{tabular}{|l|c|c|}
\hline Gender & Number of DM Patients & Percentage (\%) \\
\hline Male & 40 & 36.4 \\
\hline Female & 70 & 63.6 \\
\hline Total & 110 & 100 \\
\hline
\end{tabular}

Table.2 Distributions of total no of Diabetic patients according to age

\begin{tabular}{|l|c|c|}
\hline Age & Number of DM Patients & Percentage (\%) \\
\hline $\mathbf{2 0 - 3 0}$ & 14 & 12.7 \\
\hline $\mathbf{3 0 - 4 0}$ & 17 & 15.5 \\
\hline $\mathbf{4 0 - 5 0}$ & 21 & 19.1 \\
\hline $\mathbf{5 0 - 6 0}$ & 35 & 31.8 \\
\hline $\mathbf{6 0 - 7 0}$ & 23 & 20.9 \\
\hline Total & 110 & 100 \\
\hline
\end{tabular}

Table.3 Showing total number of parasite identified

\begin{tabular}{|l|c|c|}
\hline Parasite & Number of parasite identified & Percentage (\%) \\
\hline Entamoeba histolytica & 8 & 7.3 \\
\hline Giardia lamblia & 1 & 0.9 \\
\hline Ascaris lumbricoides & 2 & 1.8 \\
\hline Cryptosporidium parvum & 5 & 4.5 \\
\hline Total & 16 & 14.5 \\
\hline
\end{tabular}

Table.4 Showing total number of parasite identified as single and mixed infection

\begin{tabular}{|l|l|c|c|}
\hline & Parasites & $\begin{array}{c}\text { Number of DM patients } \\
\text { with parasites infection }\end{array}$ & $\begin{array}{c}\text { Percentage } \\
(\mathbf{\%})\end{array}$ \\
\hline \multirow{2}{*}{ single infection } & Entamoeba histolytica & 7 & 6.4 \\
\cline { 2 - 4 } & Giardia lamblia & 1 & 0.9 \\
\hline & Ascaris lumbricoides & 2 & 1.8 \\
\hline & Cryptosporidium parvum & 4 & 3.6 \\
\hline \multirow{2}{*}{$\begin{array}{l}\text { multiple } \\
\text { infection }\end{array}$} & Total & 14 & 12.7 \\
\hline & $\begin{array}{l}\text { Entamoeba histolytica } \\
\text { Cryptosporidium parvum }\end{array}$ & 1 & 0.9 \\
\hline & Total & 1 & 0.9 \\
\hline
\end{tabular}




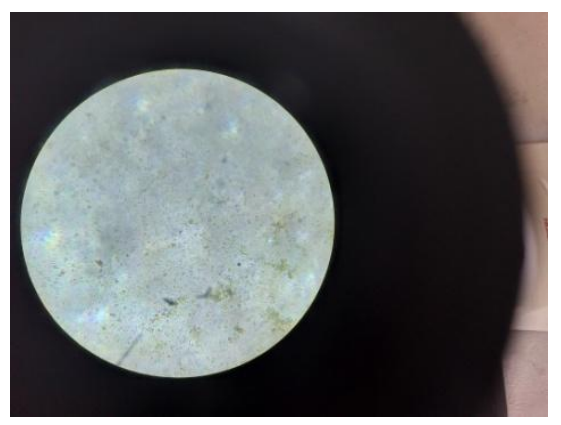

Fig.1 cyst of Entamoeba histolytica

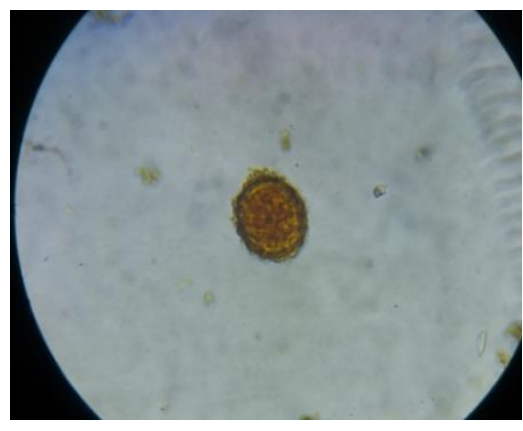

Fig.2 Ova of Ascaris lumbricoides

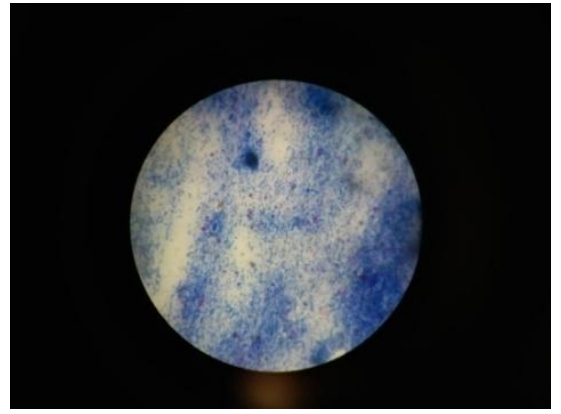

Fig.3 Modified ZN stain showing Cryptosporidium parvum

In most of the developing countries increasing DM became a major and growing health problem which became an important causes for prolonged ill health and early demise ${ }^{17,18}$. Prevalence of parasitic infection also increasing among DM patients over the world due to increasing growth of population, urbanization, aging, obesity, physical inactivity and various other factors ${ }^{19,20}$. In Asian countries proportionally DM is high in young middle age adults ${ }^{21}$.

A studied in 2013 Martiner et al., ${ }^{22}$ showed that about 382 million people suffer from DM for an overall prevalence of about $8.3 \%$. Globally, parasitic infection has been described as endemic and major causes of disease. The factors associated with parasitic infection are as poverty, illiteracy and poor hygiene, lack of proper drinking water and proper sanitary health education that may increase infection ${ }^{23}$.

Patients suffering from DM become immunocompromised and susceptible for parasitic infection. In immunocompromised patients infection of parasite become an important opportunistic pathogens which are responsible for causing illness ${ }^{24}$. The prevalence rates of parasitic infection among DM patients vary from place to place study depending upon the geographical location, study population and used of diagnostic technique ${ }^{25}$.

In this study the prevalence of the parasitic infection in DM patients was $13.6 \%$ which is lower in comparisons to the prevalence reported by different studied by Nazligul Y et al., ${ }^{26}$ as $47 \%$ and Akinbo F et al., ${ }^{9}$ as $18.7 \%$. According to study conducted by Fominyam et al., ${ }^{27}$ shows among diabetics patients prevalence of intestinal parasites was $10 \%$ and another studied conducted by Vaishali et al., ${ }^{28}$ showed $8.6 \%$ prevalence of intestinal parasites among diabetes in sub-Himalayan region of northern India which shows lower than this study. In this study mean age was 
$48.2 \pm 9.1$ years with the maximum age of 5060 years which is similar to the studied conducted by Akinbo F et al., ${ }^{9}$ and Fominyam et al., ${ }^{27}$. This may be due to the effect of ageing on weakened immune system that comes with status of diabetes mellitus. Female $(63.6 \%)$ showed higher as compare to males $(36.4 \%)$ which is comparable to the many studied as conducted by Tangi FB et al., ${ }^{29}$ and Sahar et al., ${ }^{30}$. This may be because of females are more exposes to these intestinal parasites due to engaged in farming and domestic work.

The present study showed identification of Entamoeba histolytica, Giardia lamblia, Cryptosporidium parvum and Ascaris lumbricoides from DM patients having parasitic infection whereas the study conducted by Akinbo et al., ${ }^{9}$ showed the prevalence of intestinal parasitic infections from DM patients were Ascaris lumbricoides, Entamoeba histolytica and hookworm only. Different study carried out as Fominyam et al., Entamoeba histolytica $6.7 \%$ showed higher prevelance which was similar to this study and also different from other study carried out by Nazligul Y et al., ${ }^{26}$.

In this study the prevalence of parasitic infection among DM patients was $13.6 \%$ and maximum in females. Entamoeba histolytica was most common isolated parasite followed by Cryptosporidium parvum. There is increased risk of parasitic infection in DM patients especially with Entamoeba histolytica an opportunistic infection. The diagnosis of Cryptosporidium parvum indicates a weakened immune system in diabetic's patients. This may be primary study; therefore many more study of research work is required in country. Hence for parasitic infection in DM patients should be screened routinely as stool examination for the social welfare.

\section{References}

1. Stark D, Barratt JLN, van Hal S, Marriott D, Harkness J, Ellis JT. Clinical significance of enteric protozoa in the immunosuppressed human population. Clin Microbiol Rev 2009; 22(4): 634-50.

2. Gil FF, Barros MJ, Macedo NA, et al., . Prevalence of intestinal parasitism and associated symptomatology among hemodialysis patients. Rev. Inst. Med. Trop. Sao Paulo. 2013; 55(2): 69-74. doi:10.1590/S0036-46652013000200001

3. Brink AK, Mahe C, Watera C, Lugada E, Gilks C, Whitworth J, et al., Diarrhea, CD4 counts and enteric infections in a community-based cohort of HIV-infected adults in Uganda. J Infect 2002; 45(2): 99-106.

4. Hunter PR, Nichols G. Epidemiology and clinical features of Cryptosporidium infection in immunocompromised patients. Clin Microbiol Rev 2002; 15(1): 145-54.

5. Aulagnon F, Scemla A, de Wolf S, Legendre C, Zuber J. Diarrhea after kidney transplantation: a new look at a frequent symptom. Transplantation 2014; 98(8): 806-16. Available from: http://dx.doi.org/10.1097/TP.0000000000 000335

6. K/DOQI. Clinical practice guidelines for chronic kidney disease: evaluation, classification and stratification. Am J Kidney Dis. 2002;39(Suppl 1):S11-266.

7. Marques AB, Pereira DC, Ribeiro RCHM. Motivos e frequência de internação dos pacientes com IRC em tratamento hemodialítico. Arq Ciênc Saúde. 2005;12:67-72.

8. American Diabetes Association. Diagnosis and classification of diabetes mellitus. Diabetes Care 2010; 33(Suppl 1): S62-S69. Available from: http://dx.doi.org/10.2337/dc10-S062

9. Akinbo F, Olujobi O, Omoregie R, Egbe 
C. Intestinal parasitic infections among diabetes mellitus patients. Biomarkers and Genomic Medicine. 2013; 5: 44-47. doi: 10.1016/j.gmbhs. 2013.05.003

10. www.idf.org and IDF Diabetes Atlas (6th ed.)

11. Gupta R. Mishra A. Type 2 diabetes in India: regional disparities. $\mathrm{Br} \mathrm{J}$ Diabetes Vasc Dis 2007;7(1):12-6.

12. Bessman AN, Sapico FL. Infections in the diabetic patient: the role of immune dysfunction and pathogen virulence factors. J Diabetes Complications. 1992; 6: 258-262. doi: 10.1016/10568727(92)90062-P

13. Moutschen MP, Scheen AJ, Lefebvre PJ. Impaired immune responses in diabetes mellitus: analysis of the factors and mechanisms involved: relevance to the increased susceptibility of diabetic patients to specific infections. Diabete Metab. 1992; 18: 187-201.

14. Prasad CE. Immunodeficiencies in diabetes and mycobacterial infections. Int J Diabetes Dev Countries. 1999; 19: 52-55.

15. Cheesbrough M. District laboratory practice in tropical countries. 2 nd ed updated. Cambridge University Press; 2009:183-191.

16. Cimerman S, Cimerman B, Lewi DS. Enteric parasites and AIDS. Sao Paulo Med J. 1999; 117: 266-273. doi: 10.1590/S1516-31801999000600007

17. Al-Rasheedi AA. The role of educational level in glycemic control among patients with type II diabetes mellitus. Int $\mathbf{J}$ Health Sci (Qassim) 2014;8:177-87.

18. Sami W, Ansari T, Butt NS, Hamid MRA. Effect of diet on Type 2 diabetes mellitus: A review. Int J Health Sci (Qassim) 2017;11:65-71.

19. Al-Rasheedi AA. Glycemic control among patients with type 2 diabetes mellitus in countries of Arabic gulf. Int $\mathbf{J}$ Health Sci (Qassim) 2015;9:345-50.
20. Rasheed Z, Ali R. Reactive oxygen species damaged human serum albumin in patients with Type 1 diabetes mellitus: Biochemical and immunological studies. Life Sci 2006;79:2320-8.

21. Ramachandran A, Das AK, Joshi SR, Yajnik CS, Shah S, Kumar KM. Current status of diabetes in India and need for novel therapeutic agents. $\mathbf{J}$ Assoc Physicians India 2010;58:7-9.

22. Martiner. Prevalence of Diabetes in the World 2013. Health Intelligence; 2013. p. $1-5$.

23. Mehraj V, Hatcher J, Akhtar S, Rafique $\mathrm{G}$, Beg MA. Prevalence and factors associated with intestinal parasitic infection among children in an urban slum of Karachi. PLoS One 2008;3:e3680.

24. Vaishali Moudgil, Reetima Rana, Praveen Kumar Tripathi, Umar Farooq, Rakesh Sehgal, Mohammed Azhar Khan. Coprevalence of parasitic infections and diabetes in Sub-Himalayan region of Northern India. International Journal of Health Sciences: 2019: Vol. 13, Issue 1: 19-24

25. Sarfati C, Bourgeois A, Jean M, et al., Prevalence of intestinal parasites including microsporidia in human immunodeficiency virus-infected adults in Cameroon: a cross-sectional study. Am J Trop Med Hyg. 2006; 74(1): 162-164.

26. Nazligul Y, Sabuncu T, Ozbilge H. Is there a predisposition to intestinal parasitosis in diabetic patients? Diabetes Care. 2001; 24: 1503-1504. doi: 10.2337/diacare.24.8.1503-a

27. Fominyam Boris Tangi, Eric Bertrand Fokam, Njunda Anna Longdoh and Enoh Jude Eteneneng. Intestinal Parasites in Diabetes Mellitus Patients in the Limbe and Buea Municipalities, Cameroon. Diabetes Res Open J. 2016; 2(1): 1-7. doi: 10.17140/DROJ-2-123

28. Vaishali Moudgil, Reetima Rana, 
Praveen Kumar Tripathi, Umar Farooq, Rakesh Sehgal, Mohammed Azhar Khan. Coprevalence of parasitic infections and diabetes in Sub-Himalayan region of Northern India. International Journal of Health Sciences: 2019: Vol. 13, Issue 1: 19-24

29. Tangi FB, Fokam EB, Longdoh NA, Eteneneng EJ. Intestinal parasites in diabetes mellitus patients in the Limbe and Buea municipalities, Cameroon.
Diabetes Res Open J. 2016:2;1-7.

30. Sahar Mudassar, Qurat ul Ain Javaid, Mudassar Ali2, Farheen Ansari. Comparative Study of Intestinal Parasites Isolated and Identified from Type-2 Diabetic and Non-Diabetic Population Reporting to Arif Memorial Hospital, Lahore. International Journal of Contemporary Medical Research. 2018; Volume5:Issue 1:

\section{How to cite this article:}

Dhruba Hari Chandi, Dhruba Hari Chandi and Sucheta J. Lakhani. 2020. Prevalence of Parasitic Infestation in Diabetic Patients in Tertiary Care Hospital. Int.J.Curr.Microbiol.App.Sci. 9(02): 1434-1441. doi: https://doi.org/10.20546/ijcmas.2020.902.166 